\title{
National Lexicography Units: Past, Present, Future
}

\author{
Mariëtta Alberts, Research Unit for Languages and Literature in SA Context, \\ Northwest University, Potchefstroom Campus (malberts@lantic.net)
}

\begin{abstract}
This article deals with the national dictionary offices of the previous bilingual dispensation, the eleven official national dictionary offices in the present multilingual dispensation, and the future prospects of these offices. It discusses the past dispensation in terms of the need and reasons for the establishment of national dictionary offices, i.e. national lexicography units (NLUs). Attention is given to the prescripts of the National Lexicography Units Bill (1996) for the establishment of NLUs, as well as the transfer of these units from the Department of Arts, Culture, Science and Technology to the Pan South African Language Board. The restructuring of dictionary units that existed prior to the multilingual dispensation is considered, together with the establishment of new dictionary units for the official African languages. The present situation is dealt with by describing the status quo at the NLUs in terms of housing, administration, funding, management, training, computerisation, cooperation, production and the like. The article concludes with some questions and reservations about the future of the NLUs, followed by a number of apposite recommendations.
\end{abstract}

Keywords: BILINGUAL DISPENSATION, CULTURAL DIVERSITY, GENERAL DICTIONARY, LEXICOGRAPHY, MONOLINGUAL DICTIONARY, MULTILINGUALISM, NATIONAL DICTIONARY, NATIONAL LEXICOGRAPHY UNITS, OFFICIAL LANGUAGE, TERMINOGRAPHY, TERMINOLOGY

Opsomming: Nasionale leksikografiese eenhede: Verlede, hede, toekoms. Hierdie artikel handel oor die nasionale woordeboekkantore tydens die voormalige tweetalige bedeling, die huidige meertalige bedeling waarin kantore vir die elf amptelike nasionale woordeboeke funksioneer, en die toekoms van hierdie kantore. Aspekte van die vorige bedeling word bespreek ten opsigte van die behoefte aan en redes vir die stigting van nasionale woordeboekkantore oftewel nasionale leksikografiese eenhede (NLEe). Die soeklig val op voorskrifte van die wetsontwerp oor nasionale leksikografiese eenhede (1996) vir die stigting van sodanige eenhede, sowel as op hul oordrag van die Departement van Kuns, Kultuur, Wetenskap en Tegnologie na die Pan-Suid-Afrikaanse Taalraad. Verder fokus die artikel op die herstrukturering van daardie woordeboekeenhede wat voor die meertalige bedeling bestaan het en die stigting van nuwe woordeboekeenhede vir die amptelike Afrikatale. Die huidige bedeling word ondersoek en die praktiese situasie by die NLEe word bespreek ten opsigte van behuising, administrasie, befondsing, bestuur, opleiding, rekenarisering, samewerking, produksie en dergelike. Die artikel eindig met vrae en bedenkings oor die toekoms van die nasionale leksikografiese eenhede, gevolg deur enkele aanbevelings.

Sleutelwoorde: ALGEMENE WOORDEBOEK, AMPTELIKE TAAL, EENTALIGE WOORDEBOEK, KULTURELE DIVERSITEIT, LEKSIKOGRAFIE, MEERTALIGHEID, NASIONALE LEK- 
SIKOGRAFIESE EENHEDE, NASIONALE WOORDEBOEK, TERMINOGRAFIE, TERMINOLOGIE, TWEETALIGE BEDELING

\section{Introduction}

The Memorandum on the Objects of the National Lexicography Units Bill, 1996 (DACST 1996: 16) states that "dictionaries are a mirror of a country's social, cultural, economical, scientific and technological development". With the onset of the multilingual dispensation in South Africa, indications were that the language communities of all the official languages needed national dictionaries not only to bridge the apparent communication gap between communities, but also to document the rich variety of South African languages.

The compilation of national monolingual general dictionaries would also preserve South Africa's linguistic diversity in all its forms, regardless of social, economic, political, demographic or linguistic status. The envisaged dictionaries could assist with improving citizens' understanding of the diversity of culture and language through research, advocacy, public education and community support.

Language services such as translation and interpreting, as well as institutions such as schools, tertiary institutions, libraries, the media and publishers could benefit from the national dictionary products and language services provided by dictionary units.

The proposal for the establishment of national dictionary offices was completely in line with the spirit of the Constitution (DAC 2002) in that it made equitable provision for national monolingual general dictionaries for all the official languages of South Africa with a view to the eventual promotion of multilingualism.

At the time (1995) of the drafting of the National Lexicography Units Bill, the major dictionary projects in South Africa all had different time schedules, venues and aims and it was difficult to align the projects and lexicographical activities. National lexicography (dictionary) units had to be established for all the official languages in order to create a better alignment of the State-funded part of these national dictionary projects. These units would comply both within themselves and in the broader national perspective with the goals set out in the national language policy regarding multilingualism (DACST 1996: 16).

There was (and still is) an apparent scepticism towards and total disregard for multilingualism at some institutional levels in South Africa. These sceptics might find positive pointers to the attainment of multilingualism in the endeavours of official national dictionary units. National Lexicography Units (NLUs) were namely established and managed "to make equitable provision for national general monolingual dictionaries for each of the official languages of South Africa and for matters incidental thereto" (DACST 1996: 2; Alberts 1996; DAC 2002: 7).

Political goodwill and government resources evidently had to be mobilised towards the operationalisation of constitutional multilingualism by estab- 
lishing national lexicographical units. The question that remains, however, is: "How successful are the NLUs in their contribution towards the development of the official languages within the multilingual dispensation and do they have a future?"

This article addresses the issues related to the official dictionary compilation endeavours in the period before and during the establishment of NLUs, the motivation for the establishment of these units, the establishment process itself, and the current situation where a national dictionary office was established for each of the official languages to manage the lexicographical data of these languages. It concludes with some conjecture about what the future holds for these units. The article therefore aims to give a critical historical account of the NLUs and to consider possible future scenarios for the management of institutionalised lexicographic processes.

\section{Past}

\section{$2.1 \quad$ Background}

It is the democratic right of every citizen to be empowered in any language of his/her choice in order to make a meaningful contribution to political and socio-economic activities (DACST 1996: 16; DAC 2002). The new political dispensation after 1994 thus urged the Department of Arts, Culture, Science and Technology (DACST) to make a constructive contribution to reconciliation, nation building, reconstruction and development in South Africa. The Department had no alternative but to establish NLUs to govern and manage the documentation of the vocabulary of the official languages of South Africa by giving financial support to various national dictionary projects in South Africa. By planning, managing and financing national dictionary projects, various lexicographical activities could be coordinated. DACST wanted to accomplish this in close cooperation with the Pan South African Language Board (PanSALB).

Language is a collective interest of the whole community and involves the communication needs of every person in South Africa. By establishing and funding national monolingual dictionaries, the Department could develop an umbrella lexicography policy for all official languages. At the time it was of critical importance to formulate a policy to meet the general need for a properly funded and managed lexicographical practice for the national monolingual general dictionary projects of South Africa (Alberts 1996; 1997).

A national monolingual general dictionary deals with the lexical inventory of a specific language over a broad spectrum of the vocabulary in order to describe that vocabulary in detail. This type of dictionary usually contains the general words (e.g. vernacular, common words, literary words, etymology, archaic words, dialectal variants, slang, vulgar words, core terminology of various subject areas, etc.) of the vocabulary of a specific language needed by speakers of the language needed to communicate. Such a dictionary does not 
only document the language, but also preserves it. The dictionary compilation process usually takes a number of years; the office has a permanent staff and the project is funded externally by either the State or a large publisher.

In the previous bilingual dispensation the State, through DACST, financed only two national dictionary units, namely the national Afrikaans Dictionary at the Bureau of the "Woordeboek van die Afrikaanse Taal" (WAT) in Stellenbosch and the national English Dictionary at the Dictionary Unit for South African English (DSAE) in Grahamstown.

Although the Department did not then finance any of the general dictionaries for the African languages, some public funds were made available to support these dictionary projects indirectly through university funding at various universities. Ongoing projects in an African language at that stage were the Xhosa dictionary project (English/Xhosa/Afrikaans) at the University of Fort Hare, the Zulu dictionary project at the University of Zululand, Tswana dictionary at the University of the North and a Northern Sotho dictionary project at the University of Pretoria. There were also a few private initiatives and projects of publishers regarding the compilation of general dictionaries for the indigenous South African languages. None of these projects were, however, state funded. In the post-1994 dispensation this situation of unequal government support was considered unacceptable (Alberts 1996; 1997).

Since the major dictionary projects at the time had different time schedules, venues and aims, it was difficult to align them. The Afrikaans, English and Xhosa dictionaries were ongoing projects with fixed offices, assets and staff, while those for Zulu, Northern Sotho and Tswana were university projects. A South Sotho project was also in a planning phase. All these were ongoing projects planned to last for several years. Although mostly university projects, it was clear that they also needed State funding. Two national dictionary projects planned for Swati and Tsonga respectively would probably be government projects and therefore require State funding. A need was also expressed for a Ndebele national dictionary, but no project plan had yet been submitted at that stage. It was also known that the Tshivenda Language Board was working on an English-Venda-Afrikaans glossary, although no response was received on the project during the needs assessment study that was conducted by DACST. Since this was a multilingual project it could not be considered as a national project (Alberts 1996).

In view of the constitutional provisions for multilingualism, the development of all the official languages, and the lack of alignment of State-funded dictionary projects, it was necessary to make equitable provision for the operating of national dictionary offices for all these languages. Such a dispensation required legislation along the lines of the Act governing the Woordeboek van die Afrikaanse Taal (WAT) (Act 50 of 1973, with its Amendment Acts, 9 of 1986 and 22 of 1991). This could be achieved by either amending the WAT Act or by drafting completely new legislation (DACST 1996: 16).

In 1995 DACST, funder of the WAT and DSAE dictionary projects, decided to draft legislation to establish national lexicography units for all the offi- 
cial languages. The ensuing Bill made provision for dictionary units for all the official languages. The linguistic heritage of the country could be preserved and further developed in these units seeing that general lexicography comprehensively describes the vocabulary of a given language by documenting it. The Bill was supposed to bring about change and transformation.

By supporting monolingual dictionary projects, the policy of multilingualism was also maintained since it involved the documentation of all the official indigenous languages. By planning, managing and financing national dictionary projects, DACST intended to coordinate lexicographic activities in South Africa and eliminate the possible duplication of work. Thus, DACST aimed to finance the dictionary units (as was already the case with Afrikaans and English) and to provide recurrent State financing to the NLUs. The envisaged establishment of the units was advertised widely in the media. Media coverage would ensure the correct positioning of the dictionary units to be established and attract appropriate collaborators to work on these projects.

Various bodies such as the Language Task Group (Langtag), the Langtag Subcommittee for the Development of the (South) African Languages, the Pan South African Language Board (PanSALB), the African Association for Lexicography (Afrilex), the Board of the "Woordeboek van die Afrikaanse Taal" (WAT), the Portfolio Committee on Arts, Culture and Language, Science and Technology, the Select Committee on Education, Sport and Recreation, Arts, Culture, Science and Technology, the Task Group appointed to revise the WAT Act, the departmental legal adviser, departmental consultants and 98 stakeholders in the field of lexicography were consulted, and various needs assessment studies were conducted (Alberts 1996).

It was obvious from the reaction of stakeholders that responded to the proposed revision of the existing WAT Act that they all welcomed the establishment of the envisaged National Lexicography Units. The respondents were all satisfied with the idea of an umbrella Act to govern general monolingual dictionary projects for the official languages of South Africa. The Task Group appointed to revise the WAT Act discussed the suggestions made by respondents and these suggestions were incorporated in the Bill (Alberts 1996).

The Department (DACST) subsequently recommended that the existing WAT Act (Act 50 of 1973, with its Amendment Acts, 9 of 1986 and 22 of 1991) be repealed and replaced by a new Act (the National Lexicography Units Bill) to govern national lexicography (dictionary) units for the official languages (Alberts 1996).

\subsection{The National Lexicography Units Bill}

In 1995 the National Lexicography Units Bill was drafted as umbrella legislation to incorporate the existing WAT and DSAE dictionary units, and to make provision for the establishment of national dictionary units for each of the official South African languages (Alberts 1996; DACST 1996). According to the Bill, 
each national lexicography (dictionary) unit would be managed by an Editorin-Chief who would be accountable to a Board of Directors as management committee. The Board of Directors (BoD) was to be appointed by the Minister of Arts, Culture, Science and Technology (ACST) in consultation with stakeholders and it would in turn be accountable to the Minister of ACST. The individual BoD of each NLU would appoint the Editor-in-Chief for its NLU as well as the staff. The BoD also had the power to dismiss any person appointed. The NLUs would be managed as section 21 companies and although financed by the State, they would be able to generate their own funds. The NLUs would furnish DACST with annual and financial reports (Alberts 1996; 2003).

Every NLU would have a fixed staff component and the State undertook to finance the dictionary projects as long as possible or necessary (Alberts 1996; 1997).

The Bill stipulated that the NLUs should be situated at tertiary institutions in the relevant geolinguistic area where the bulk of first-language speakers reside. The tertiary institutions could provide the necessary infrastructure and administrative facilities while the academic staff teaching the respective languages could be included in the editorial committees. The involvement of linguists would bring the dictionary products in line with the overall development and standardisation of the respective languages. First-language speakers in the geolinguistic areas concerned would obviously be stakeholders in the dictionary compilation process and would be available for fieldwork and the gathering of linguistic data (Alberts 1996).

Although the use of the official languages is not limited to specific geolinguistic areas, it was decided not to relocate existing decentralised dictionary units such as the WAT and DSAE since this would disrupt and even destroy infrastructure and support systems that were developed over time (Alberts 1996). In an era where computers rule the world, a coordinated approach towards the compilation of dictionaries does not require centralisation of dictionary offices, resources or facilities. In fact, centralisation could well detach dictionary making from the speech communities concerned and undermine the independence, resources and skills of minor language groups and under-resourced regions (Alberts 1996; 1997).

In order to develop the necessary capacity to achieve lexicographical goals such as the compilation, editing and publishing of dictionaries, the staff appointed at the WAT and DSAE, as well as the newly appointed staff of the new dictionary units required training pertaining to lexicographical principles and practice. Several institutions, bodies or associations skilled in lexicographical principles and practice, e.g. universities presenting courses in lexicography, the African Association for Lexicography (Afrilex) and existing dictionary units (e.g. WAT and DSAE) indicated that they could provide the required training to staff of the envisaged dictionary units (Alberts 1996).

The National Lexicography Units Bill served before the Cabinet's Committee on Social and Administrative Affairs on 12 June 1996 and was summarily approved. The Bill then served before Cabinet on 19 June 1996, and input 
from the Chief State Law Adviser was received on 18 September 1996. Officials from DACST's National Terminology Services (NTS) met with the Portfolio Committee: Arts, Culture and Language, Science and Technology on 14 February 1997 to discuss suggestions made by the Portfolio Committee. Once these suggestions had been incorporated, the Bill was ratified (Alberts 1996; DACST 1997).

\subsection{PanSALB and the tabling of the National Lexicography Units Bill}

The former Minister of Arts, Culture, Science and Technology, Dr Ben Ngubane, requested the revision of legislation pertaining to the Afrikaans dictionary project at the Bureau of the "Woordeboek van die Afrikaanse Taal" with a view to covering the governance of the envisaged national lexicography units (NLUs) for the official South African languages. The aim with the new legislation was also to ensure greater equity in allocating resources to the different NLUs (DACST 1996; DACST 1997).

After wide consultation with various stakeholders in the field of lexicography (see § 2.1), a Bill — the National Lexicography Units Bill — was drafted by the Task Group appointed for this task (see § 2.2). It was obvious from the reaction of respondents to the questionnaires and working documents related to the Bill that they were looking forward to the establishment of the envisaged NLUs. As mentioned earlier, the respondents were all satisfied with the idea of an umbrella Act to govern national general dictionary projects for the official South African languages (DACST 1997).

During discussions in the Minister's office regarding possible amendments to the Pan South African Language Board Act (Act 59 of 1995), the future process regarding the establishment of the NLUs was again raised. The discussions focused mainly on the future role of PanSALB, but various issues were considered - among others the relationship between PanSALB and the envisaged lexicography units (DACST 1997).

It was recommended that the Minister consider the relationship between PanSALB and the envisaged NLUs, and discuss this matter with the Executive and Board of PanSALB. It was further recommended that the issue be discussed with the Chairperson of the Portfolio Committee: Arts, Culture and Language, Science and Technology. Political binding had to be received before the end of April 1997, since the policy review of the whole language issue was at stake (DACST 1997).

In 1998 DACST revised and amended the Pan South African Language Board Act, Act 59 of 1995 and one of the major proposals to these amendments was that the Board "shall in the manner prescribed by notice in the Gazette and the provincial Gazette establish NLUs for each of the official languages of South Africa" (PanSALB 1998: 14). The PanSALB Board did not approve the proposal from DACST and suggested that the National Lexicography Units Bill 
be resubmitted to be passed as an Act of Parliament as a matter of urgency (PanSALB 1998: 14).

The amended PanSALB Act (PanSALB Amendment Act 1999), however, placed on PanSALB the responsibility to establish "national lexicographic units that will operate as companies limited by guarantee under section 21 of the Companies Act No 61 of 1973" (PanSALB 1999: 28). The articles of the National Lexicography Unit Bill were incorporated as resolutions into the revised PanSALB Act, and the NLUs were to be established as structures of the Pan South African Language Board.

In terms of the PanSALB Amendment Act, 1999, Section 8 (2) (c), the Board had to establish the following (PanSALB 1999: 19; 2000: 26):

"Units to operate as companies limited by guarantee under section 21 of the Companies Act, 1973 (Act 61 of 1973) and shall allocate funds to the units for the fulfillment of their functions. Provided that the memorandum and articles of association of such units shall include the following principles:

(i) The unit is accountable to the Board for the moneys allocated to it.

(ii) The unit shall abide by the policies of the Board.

(iii) The unit shall adhere to the principles of promoting language development."

The Bureau of the Woordeboek van die Afrikaanse Taal (WAT) operated in terms of the "Woordeboek van die Afrikaanse Taal" Act, 1973 (Act 50 of 1973). The Bureau of the WAT had been registered as a section 21 company to await the promulgation of the repealed WAT Act, after which it ceased to function as a statutory body and had the same status as the other NLUs in the country (PanSALB 2001: 22).

The Dictionary of South African English (DSAE) had been operating as a section 21 company since 1991 and functioned under the auspices of PanSALB since April 2001 (PanSALB 2001: 22).

The subsidies that DACST used to pay to the Bureau of the WAT and the DSAE were thenceforward to be handled by PanSALB. An equitable distribution of subsidies to all NLUs countrywide would be pursued over the next ten years (PanSALB 2001: 22).

\subsection{The establishment of the National Lexicography Units (NLUs)}

PanSALB realised the need for coordinating all the isolated efforts in the country so as to formulate a strategy for lexicography and terminology development in respect of all the official languages in the country, particularly the previously marginalised languages. On 31 October 1997 a consultative meeting of stakeholders was held in Johannesburg. Two follow-up meetings took place in 1998: the first on 19 and 20 March for those languages with existing dictionary 
units, and the second on 14 and 15 May for those languages without dictionary units. Norms and regulations for the establishment and recognition of lexicography units were discussed with delegates on these occasions and the reports on the proceedings of these meetings were published by PanSALB (PanSALB 1998: 11).

A meeting for existing dictionary units was held from 25 to 27 August 1999 in Pretoria to develop a strategic planning framework for each unit and to do lexicographic planning (PanSALB 1999: 20).

These processes assisted the Board in the effective handling of its new responsibility of establishing lexicographic units and actions were developed to facilitate the establishment of such units. The norms and regulations for establishing lexicographic units were translated into all the official languages and gazetted by government notice to facilitate this process (PanSALB 1999: 28).

The main purpose of the units would be to "conserve, preserve, research and document the official languages concerned, by compiling a monolingual explanatory dictionary and such other dictionaries as may be required to satisfy the needs of the target users of that language" (PanSALB 2000: 26).

Consultative meetings were held in 1999 with various stakeholders and role-players from the different official languages with the aim of informing them of the nature of section 21 companies, the main purpose of the dictionary units, and to elect founder members (PanSALB 2000: 26).

By March 2001 a national lexicography unit (NLU) for each of the official languages in South Africa had been established and registered as a section 21 company.

\subsection{Training workshops for NLUs}

As mentioned above, between August and November 1999 PanSALB held four workshops for those languages that already had lexicography units, as well as for those languages for which units had to be established. The workshops were attended by staff already working in dictionary offices and other people involved in lexicography projects on an individual and part-time basis, such as university lecturers who were compiling dictionaries (PanSALB 2000: 26).

The training sessions dealt with strategic and lexicography planning. Vision and mission statements were formulated and guidance was given for the setting of lexicographic goals and the formulation of action plans. Training also focused on the computerisation of dictionary compilation processes at the dictionary units (PanSALB 2000: 26).

Expert lexicographers from within South Africa and abroad dealt with topics such as the following (PanSALB 2000: 26):

- Different types of dictionaries and their nature

- Data collection policies and the creation of a database 
- Inclusion policies

- Lexicography processes and data types

- Dictionary design and layout

- Computers and computer literacy in lexicography

- Computer programs (software) and corpus building

\section{Present}

\subsection{NLUs: Accommodation and venue}

The National Lexicography Units Bill stipulated that national lexicography units should be established at a tertiary institution in the geolinguistic area where the most first-language speakers of the relevant language reside (National Lexicography Units Bill 1996). At the different consultative meetings held during 1997 and 1998 it was decided that "the units should be established at or close to a tertiary institution where the language concerned is taught and where there is a concentration of mother-tongue speakers" (PanSALB 2000: 2627).

In 1999 PanSALB held meetings with the following universities and institutions to secure accommodation for NLUs:

- IsiXhosa: the University of Fort Hare (the Greater Xhosa Dictionary project > isiXhosa National Lexicography Unit), Alice - NLU registered as a section 21 company in 2001.

- IsiZulu: the University of Zululand (Isikhungo Sesichazamazwi SesiZulu), Umlazi Campus - project established in 1981. NLU registered as a section 21 company in 2000.

- Sesotho sa Leboa: the University of the North (Sepedi Dictionary Unit > Sesotho sa Leboa Dictionary Unit), Pietersburg/Polokwane - NLU registered as a section 21 company in 2000.

- Xitsonga: Tivumbeni College of Education (Yuniti Ya Lekisikhogirafi ya Xitsonga), Tzaneen - NLU registered as a section 21 company in 2001.

- Setswana: University of Northwest (Sefala sa Setswana), Mmabatho NLU registered as a section 21 company in 2001.

- Siswati: Pretoria Technikon Nelspruit Campus (Silulu Sesiswati Lexicography Unit), Nelspruit (PanSALB 2000:27) — NLU registered as a section 21 company in 2001.

Accommodation was at the time (1999) (PanSALB 2000: 28; 2001: 25) also secured for 
- Afrikaans: the University of Stellenbosch (Die Woordeboek van die Afrikaanse Taal (WAT)), Stellenbosch — c. 1930, NLU registered as a section 21 company in 2000.

- English: Rhodes University (Dictionary of South African English), Grahamstown - c. 1969, in existence as a section 21 company since 1991.

- IsiNdebele: the University of Pretoria (IsiNdebele Dictionary project), Pretoria - NLU registered as a section 21 company in 2000.

Accommodation was later secured (PanSALB 2001:25) for

- Sesotho: University of the Free State (Sesiu sa Sesotho NLU), Bloemfontein - NLU registered as a section 21 company in 2001.

- Tshivenda: University of Venda (Tshivenda NLU), Thohoyandou NLU registered as a section 21 company in 2001.

\subsection{NLUs: Management structures}

The NLUs at the outset consisted of two management structures: members and directors. Members of the companies were elected during consultative meetings, e.g. annual general meetings. Directors were nominated by institutions, structures and bodies in terms of article 41 of the articles of association (PanSALB 2000: 27).

The Boards of Directors (BoDs) that controlled and managed the NLUs consisted of eleven directors each. They appointed the editors-in-chief and the requisite staff members who compiled the dictionaries and managed the offices (PanSALB 2000: 27). The Boards of Directors were also responsible for the development, adaptation and implementation of strategic planning frameworks for all NLUs (PanSALB 2000: 30).

PanSALB developed guidelines for the reporting by an NLU to its Board of Directors, the reporting of NLU Boards of Directors to PanSALB, and the reporting of PanSALB to DACST (PanSALB 2000: 30). Guidelines were provided regarding progress and financial reports.

\subsection{NLUs: Memorandum and articles of association}

Every NLU operating as a section 21 company was to be governed by two constitutive documents:

- A Memorandum of Association (MoA) - the founding document of a company to which the founder members are signatories

- Articles of Association (AoA) - the document that determines the manner in which a company is supposed to function (PanSALB 2000: 27) 
These documents were drafted by PanSALB in a form adaptable to the unitspecific characteristics of each unit and language group. The norms and regulations for the establishment of the NLUs developed at the consultative meetings were integrated with the constitutive documents of the companies and replaced by the MoA and AoA in accordance with the Companies Act, 1973 (Act 61 of 1973). These documents were continually being reworked and redesigned during the process of the establishment of the NLUs in an effort to take unit-specific factors into account (PanSALB 2000: 27).

In 1999 PanSALB appointed a practising attorney to draft powers of attorney and to lodge the prescribed forms with the Office of the Registrar of Companies in terms of the Companies Act once the companies (NLUs) were ready for registration (PanSALB 2000: 27).

\subsection{NLUs: Funding and financial management}

Since the establishment of the national lexicography units, PanSALB has been continually involved in negotiating funding for the NLUs with DACST and the National Treasury (PanSALB 2001: 23). Liaison and negotiations regarding funding for NLUs were handled through DACST (PanSALB 2000: 30).

PanSALB devised a ten-year plan for the attainment of funding equity between the NLUs. This plan was submitted to the Minister of Arts, Culture, Science and Technology for approval (PanSALB 2001: 23).

Funding is released on a monthly basis to the units upon receipt of a business plan and a budget. These are based on strategic planning documents compiled during workshops with role-players. Representatives from the units received guidance from PanSALB with regard to strategic planning focusing on short-, medium- and long-term goals, environmental analysis, future strategic positions, plans of action, etc. (PanSALB 2001: 23).

\subsection{NLUs: Staff}

Three NLUs, i.e. the Bureau of the WAT, the Xhosa Dictionary Project and the Zulu Dictionary Unit, initially operated as either statutory bodies funded by government (Bureau of the WAT) or as projects at tertiary institutions (the Xhosa and Zulu projects). The transitional provisions in the Repeal WAT Act made provision for the transfer of the staff of the Bureau of the WAT as a statutory body to the Bureau as a section 21 company (PanSALB 2001: 23). In the case of the Xhosa and Zulu projects the situation was more complicated since their personnel were employed and paid by the tertiary institutions that funded these projects (i.e. the universities of Fort Hare and Zululand respectively). These staff members had to enter into new service contracts with the section 21 companies, and PanSALB assisted the units and their staff in negotiating service benefits (PanSALB 2001: 23). 
The newly established NLUs appointed staff members and offered employees fixed-term contracts. In these cases PanSALB provided the Boards of Directors with guidance on the organisational structure of an NLU, job specifications, and the terms and conditions of appointment (PanSALB 2001: 23-24).

\subsection{NLUs: Administrative support, planning and functioning}

Staff members in PanSALB's Lexicography and Terminology Development focus area managed the NLUs in terms of measuring progress with dictionary production and assisting with capacity building to strengthen the operation of these units. The focus area supplied administrative, training, financial and technical support to the NLUs. Assistance was given regarding the development of three-year strategic plans, as well as annual budgets and action plans. PanSALB transferred funds to the NLUs via the universities where the units are situated. The Editors-in-Chief were required to submit quarterly reports to PanSALB, including financial reports to ensure that NLUs' compliance with the relevant regulations could be monitored (PanSALB 2003/2004: 6; 2004/2005: 32; 2005/2006: 26; 2007/2008: 35). NLUs were furthermore assisted with the management of staff according to human resources prescripts (PanSALB 2003/ 2004: 6; 2004/2005: 32).

The Lexicography and Terminology Development focus area also established an information support service (PanSALB 2000: 30), guidance to NLUs with regard to procurement policies for information resources, and essential reference works that should be consulted during the lexicographic process (PanSALB 2001: 24; 2001/2002: 12). The NLUs obviously require permanent access to essential dictionaries, encyclopaedias, reference works and other information resources.

Copyright issues had to be solved - not only for the NLUs to obtain copyright clearance from the publishing companies to access material (i.e. to scan books and electronic material during the process of corpus building that leads to dictionary compilation) (PanSALB 2001/2002: 12), but also to safeguard the products of the NLUs (Alberts and Jooste 1998: 122-139). It was therefore suggested that the NLU Boards of Directors had to ensure that the service contract of every employee should include a clause to the effect that copyright in any work produced by the employee during his/her employment at the Company (NLU) would vest in the Company (NLU) (Alberts 2003).

The focus area staff and members of the Board visited the NLUs regularly to monitor progress and provide assistance where needed (PanSALB 2003/ 2004: 6-7).

NLUs were also assisted with the marketing of the units and the obtaining of community involvement (PanSALB 2004/2004: 7).

\subsection{NLUs: Co-operative lexicography}

The idea of co-operative lexicography already manifested itself in 1991 when it 
was suggested that an institute for Southern African lexicography be established under the control of the then envisaged Pan-South African Language Board. In an attempt to concretise the idea of co-operative lexicography, the Board of Control of the WAT requested in 1992 that a feasibility study on the creation of an Institute for Southern African Lexicography be undertaken. This study was completed in July 1993 by an external research team led by the author.

The report, Feasibility Study: Institute for Southern African Lexicography, contained information that was indispensable for the further planning of lexicographical practice in South Africa. The report was based on questionnaires sent to 186 State-supported lexicographical projects and language offices, associations, private lexicographers, publishers, educational or cultural committees of political groupings, lecturers teaching lexicography, lexicographers at universities, various opinion formers, Ministers and MECs responsible for education and/or cultural affairs, and language boards (Alberts 1993).

Although the research indicated that an Institute for Southern African Lexicography was viable, it also showed that the important role-players did not feel the need for such a body. The success of the institute would rely on their collaboration. Respondents were afraid of a governing body with enforceable power. There was, however, a great need for collaboration, co-operation, coordination and communication. The respondents did not want an authoritative and bureaucratic body. They required a flexible structure with a lot of freedom. It was decided to establish an association for lexicography and thus the African Association for Lexicography (Afrilex) was founded in 1995. Lexikos of the Afrilex Series of the Bureau of the WAT served as its accredited journal and mouthpiece (Alberts 1993). Since its establishment, Afrilex supported co-operative lexicography and terminology through its international conferences, symposia and the publication of excellent articles in the Lexikos journal.

The lexicographic products rendered by lexicographers at the NLUs are used by a wide spectrum of target users, inter alia by learners, students, educators, academics, the economic sector, scientists, language practitioners, etc. It is therefore essential for lexicographers and other parties interested in the field of lexicography to co-operate as extensively as possible. Such co-operation may take place at various levels, including within and between national dictionary units, with members of the speech community, with language departments at tertiary institutions, with language bodies (i.e. National Language Bodies and Provincial Language Committees), with government and semi-governmental institutions, with associations for lexicography and terminology (i.e. Afrilex, Prolingua, ISO TC/37, SABS TC 37), with the private sector, with language practitioners such as translators, interpreters and terminologists, and with the media.

PanSALB had (and still has) a policy of actively promoting the notion of "co-operative lexicography" (PanSALB 2001: 24). The Board established systems of co-operation among all existing NLUs and other lexicographers nationally, 
and obtained particulars of relevant stakeholders (PanSALB 2000: 30; 2001: 2425). The experience in practical lexicographical work gained by the WAT and DSAE was shared freely with the other nine African language NLUs (PanSALB 2001/2002: 9).

Lexicographers at the NLUs had to seek input and feedback from target and end users of lexicographic products on a regular basis. By sharing information and expertise, the lexicographical process and products could be improved and promoted worldwide. The NLUs also initiated cross-border co-operation with countries sharing the same languages, especially in the case of marginalised languages (PanSALB 2004/2005: 38).

The NLUs were encouraged to submit their dictionary products to the relevant National Language Bodies (NLBs) for verification of the language matter (e.g. spelling and orthography conventions; word-forming principles) (PanSALB 2003/2004: 7). Closer collaboration between the NLUs and NLBs would greatly enhance the development of the various languages.

The NLUs were requested to become involved in the Human Language Technologies (HLT) project that was the brainchild of DACST and PanSALB (PanSALB 2001/2002: 11-12; 25-27). The HLT initiative could well lead to the establishment of an HLT industry in South Africa that will support translation and interpreting services, while the NLUs could provide crucial linguistic data to the project.

As part of the Afrilex Series, the Bureau of the WAT published various issues of Lexikos, a journal for lexicographers containing articles by authors from South Africa, other African countries and Europe - all who are experts in the field of lexicography.

\subsection{NLUs: Training}

PanSALB facilitated lexicography planning by assisting NLUs with information and training on issues such as data collection norms for dictionaries, norms for the inclusion and establishment of micro- and macrostructures for each dictionary project, and developing an editorial style guide for each dictionary to be compiled by a lexicography unit (PanSALB 2000: 30).

In 1999 PanSALB facilitated the training of the editors-in-chief, boards of directors and staff of existing NLUs in the principles and practice of lexicography; metalexicography; the use of computer hardware and software; the planning of projects and the management of NLUs; negotiation skills and marketing (PanSALB 2000: 30).

Follow-up training sessions were held for existing NLUs in October 2000 and in February 2001 for newly established NLUs. Topics covered at these workshops included the following (PanSALB 2001: 22):

- Directors' briefs (the King Code of Corporate Practices and Conduct)

- Drafting of business plans and budgets 
- $\quad$ Reporting procedures

- Organisational structures and job descriptions

- Terms and conditions of employment

- Advertising and recruiting

Between 27 and 29 November 2000, staff members of existing NLUs were also given the opportunity to attend a training course entitled: An introduction to theoretical lexicography and its practical applications. The course was repeated at the end of March 2001 for suitable candidates identified by the boards of directors of the newly established NLUs. Prof. Rufus Gouws of the University of Stellenbosch was contracted by PanSALB to facilitate these training courses (PanSALB 2001: 23).

Prof. Gouws was also contracted by PanSALB in 2000 to facilitate, review and revise the then current and proposed projects at existing units, to assist newly established units in deciding what type of dictionary to compile first and to assist with the formulation of a dictionary conceptualisation plan and instruction book. This resulted in an action plan for the secondary lexicographic process within the NLUs (PanSALB 2001: 24). Prof. Gouws trained the staff at the units (PanSALB 2001/2002: 11) and training themes included the following:

- Dictionary typology

- The structure of dictionaries

- Frame structure

- Textbook structure

- Macrostructure

- Microstructure

- Access structure

- Mediostructure (i.e. cross-referencing)

- Linguistic data and the presentation thereof in dictionaries

On 25 and 26 February 2002 a two-day training workshop on The lexicographic process of the NLUs: Progress and planning was held at the CSIR Conference Centre in Pretoria (PanSALB 2001/2002: 11). The training offered covered the following issues:

- The lexicographic process in the NLUs: recent issues

- Lexicographic management: the board of directors and the staff of the NLUs

- Contracts and legal matters

- Continued PanSALB support

- Implementing a dictionary plan 
- Compiling and using corpora

- Using Onoma software

- Co-operation between the DSAE and the other NLUs

Prof. Gouws went on to develop a three-phased training plan on lexicographic planning on behalf of PanSALB (PanSALB 2001/2002: 11):

- Phase one: General theory of lexicography

- Phase two: Problems related to language groups

- $\quad$ Phase three: Language-specific features and problems

During the 2003/2004 financial year, four workshops were held for the staff of the NLUs aimed at improving the quality of lexicography work at the units. The following issues were addressed:

- Administrative and financial skills

- Improving the quality of lexicography work at the NLUs

- Training of Editors-in-Chief on managing NLU offices and staff (Alberts 2003)

_ Improving computer skills of NLU staff (PanSALB 2003/2004: 6)

\subsection{NLUs: Computerisation}

In 2000, needs assessment studies with regard to computer hardware and software were undertaken by PanSALB at nine of the NLUs (PanSALB 2001: 24; 2001/2002: 11). The Bureau of the WAT started the computerisation of its lexicographic data by using the Lexi program developed especially for the WAT by the Human Sciences Research Council, while the DSAE was using X-Write software.

PanSALB established a relationship with a Swedish company on computational linguistics called Lexilogik AB. Their flagship program, Onoma, replaced the Lexi program at the Bureau of the WAT. PanSALB and Lexilogik AB concluded a contract at the end of March 2001 with regard to the computerisation of the other NLUs. After a detailed project plan had been drafted during a visit to South Africa by Lexilogik AB at the end of March 2001, the Onoma program was installed at the Sesotho sa Leboa and isiNdebele NLUs (PanSALB 2001: 24).

PanSALB contracted Prof. Daan Prinsloo of the University of Pretoria to assist the NLUs with the process of computerising collected data into a corpus (PanSALB 2001/2002: 11). This process entailed primary practical corpus building and dictionary compilation by using software. The training was done at the NLUs and continued during the 2003/2004 financial year. Prof. Prinsloo 
assisted with the following issues (PanSALB 2003/3004: 6-7; 2004/2005: 32):

- Computer literacy of staff

- Improving computer skills of NLU staff

- Consultation of reference material

- Knowledge of information sources

- Data collection norms and policies

- Development and building of databases

- Development and building of corpora

- Expansion of corpora

- Use of the Internet and accessing of electronic data

- Strengthening the NLUs' information technology (IT) systems

- Putting systems in place to produce small dictionaries and other lexicographic products

The TshwaneLex dictionary production software that was developed in South Africa was demonstrated to PanSALB and in the 2004/2005 financial year the Board approved the obtaining of TshwaneLex licences for the eleven NLUs during the next financial year (PanSALB 2004/2005: 32; 2005/2006: 26). The staff of the NLUs received training in the use of TshwaneLex once the program had been installed at the units.

\subsection{NLUs: Dictionary products}

The ultimate goal of the NLUs is to produce dictionaries. The facilities, funding, guidance and training provided since the establishment of the units were efforts to accelerate the process of producing suitable and needed dictionaries for the local speech communities (PanSALB 2001/2002: 12).

\section{Afrikaans NLU}

- Volume XII of the Woordeboek van die Afrikaanse Taal, containing the letters $\mathrm{P}$ and Q was published in 2005 (PanSALB 2004/2005: 32).

- The electronic version of the Woordeboek van die Afrikaanse Taal ( $A$ tot O) (Elektroniese WAT) was made available in 2003 through the websites of six South African universities: Stellenbosch, Free State, Pretoria, Johannesburg, Northwest (Potchefstroom Campus) and South Africa (UNISA) (PanSALB 2004/2005: 33). The Elektroniese WAT (A tot Q) followed in 2006 (Wolvaardt 2008). 
- An Afrikaans synonym dictionary was published in 2006 (PanSALB 2004/2005: 33; 2005/2006: 28; Wolvaardt 2008).

- An etymology dictionary of Afrikaans was published in 2005 (PanSALB 2005/2006: 28), with a Supplement that followed in 2007 (Wolvaardt 2008).

- $\quad$ New project: Volume XIII of the Woordeboek van die Afrikaanse Taal was published in 2009 (Wolvaardt 2008).

\section{English NLU}

- A Dictionary of South African English on Historical Principles (DSAEHist) was published in 1996 (Wolvaardt 2008).

- The DSAE edited the South African Concise Oxford Dictionary that was published by Oxford University Press (South Africa) in 2002 (PanSALB 2004/2005: 33).

- Research was done for a revision of the Illustrated School Dictionary for Southern Africa (PanSALB 2004/2005: 33).

- Additional material was identified for a revision of the Dictionary of South African English on Historical Principles (PanSALB 2004/2005: 33).

- The DSAE developed a comprehensive 'Reading and Intake Strategy' in order to ensure that research undertaken covers a broad range of South African English (PanSALB 2004/2005: 33).

- Other publications included the following:

- South African Concise Oxford Dictionary (SACOD) (6th Impression, Nov. 2006) (Wolvaardt 2008)

- Editorial consultants SA English: Encarta World Dictionary 2004 (Wolvaardt 2008)

- $\quad$ Oxford Dictionary of English 2005 (Wolvaardt 2008)

- Database of South African English, in progress (Wolvaardt 2008)

- $\quad$ SACOD 2nd edition, in progress (Wolvaardt 2008)

- $\quad$ DSAEHist, 2nd edition, in progress (Wolvaardt 2008)

\section{IsiXhosa NLU}

- (Former Xhosa Dictionary Project, 1968). Volume 2 (letters K to P) of the Trilingual Dictionary (Xhosa, English and Afrikaans) was published during the 2004/2005 financial year (PanSALB 2004/2005: 34).

- Volume 1 of the Trilingual Dictionary (letters A to J) was finalised (PanSALB 2004/2005: 34; 2005/2006: 28).

- The Greater Dictionary of Xhosa was published as follows: Vol. 2 in 2003, Vol. 1 in 2006 and Vol. 3 in 1989 (Wolvaardt 2008). 
- A monolingual dictionary was published in 2008.

- A new project involves the compilation of a Maths, Science and Technology dictionary for Grades 4 to 6 (Wolvaardt 2008).

\section{IsiZulu NLU}

- The unit finalised the editing of a comprehensive monolingual Zulu dictionary (PanSALB 2004/2005: 35). This dictionary, Isichazamazwi Sesizulu, was launched in 2007 (PanSALB 2007-2008: 35) (earlier shorter versions, 1982 and 1985) (Wolvaardt 2008).

- The first draft of an isiZulu-English bilingual dictionary was published in 2010 (final product due in March 2012) (PanSALB 2009/2010: 43).

\section{Siswati NLU}

- The unit finalised the compilation of a draft English/Siswati dictionary. The draft was published and circulated to all stakeholders for comments and recommendations (PanSALB 2004/2005: 37), after which the Silulu sesiSwati/Swati Bilingual Dictionary (Siswati/English) was launched in 2007 (PanSALB 2007-2008: 35).

- The draft bilingual dictionary was launched in SA and Swaziland, and editing for its final publication is in progress (Wolvaardt 2008).

- The work on a Siswati monolingual dictionary was placed on hold in order to complete the bilingual draft (PanSALB 2004/2005: 37). A new project involving a monolingual dictionary is in progress (Wolvaardt 2008).

\section{IsiNdebele NLU}

- The NLU continued with the compilation of the English/IsiNdebele explanatory dictionary (PanSALB 2004/2005: 37; 2005/2006: 29) that was published in 2010 (PanSALB 2009/2010: 43). A monolingual dictionary was published in 2009 (Wolvaardt 2008).

- A draft bilingual scholars' dictionary was launched in March 2006 (Wolvaardt 2008).

- A new project that is under way involves a trilingual English, Afrikaans and isiNdebele dictionary (Wolvaardt 2008).

\section{Sesotho sa Leboa NLU}

- The NLU transferred the lemmas for the comprehensive monolingual dictionary from the records held in MS Word to TshwaneLex. A draft 
dictionary was presented to stakeholders at the NLU's annual general meeting in 2004 (PanSALB 2004/2005: 36). The dictionary Pukuntsuthalosi ya Sesotho sa Leboa - Volume I (Monolingual Dictionary) was launched in 2008 (PanSALB 2007-2008: 35; Wolvaardt 2008).

- Work was done on the compilation of a bilingual Sesotho sa Leboa/ English dictionary (PanSALB 2004/2005: 36). A draft copy was published in 2005 (PanSALB 2005/2006: 30) and the dictionary was launched in 2008 (PanSALB 2007-2008: 35).

\section{Sesotho NLU}

- The unit completed the letters A to E of the draft bilingual Sesotho/English dictionary during the financial year 2004/2005 (PanSALB 2004/2005: 35). The English-Sesotho dictionary was published in the 2008 financial year (Wolvaardt 2008).

- The unit aimed to commence work on a Sesotho monolingual dictionary (PanSALB 2004/2005: 35). A corpus of 4,160,362 running tokens was built, and six additional Sesotho books were scanned and OCR errors cleaned up for inclusion in the corpus (Wolvaardt 2008).

- A mini scholars' bilingual dictionary produced by the unit was published in 2005 (PanSALB 2005/2006: 31).

- A primary school dictionary with 3371 lemmata/headwords with Sesotho equivalents was compiled (Wolvaardt 2008).

\section{Setswana NLU}

- The unit prepared a mini dictionary during the 2004/2005 financial year and the lexicographical data was sent to various language experts for editing and quality control (PanSALB 2004/2005: 36).

- The unit aimed to start work on a bilingual Setswana/English dictionary (PanSALB 2004/2005: 36).

- A monolingual dictionary was compiled and sent through a consultative process for verification (PanSALB 2005/2006: 30). The monolingual manuscript was completed in June/July 2006, and a process of review and editing is currently in progress (Wolvaardt 2008).

\section{Xitsonga NLU}

- The NLU continued work on a bilingual explanatory Xitsonga/English dictionary. The English/Xitsonga section had been completed and work was done on the reverse side, namely the Xitsonga /English section (PanSALB 2004/2005: 36). The dictionary was published in 2005 (PanSALB 2005/2006: 31). 
- Work on a comprehensive monolingual Xitsonga dictionary project was started in 2004 (PanSALB 2004/2005: 36; 2005/2006: 31).

- Both bilingual and monolingual draft dictionaries were presented for consideration at the unit's annual general meeting in 2005 (PanSALB 2004/2005: 36). The monolingual dictionary was published in 2009 (Wolvaardt 2008).

- Revised Terminology No. 3 was published in March 2009 (Wolvaardt 2008).

- A Xitsonga traditional dictionary was launched in the 2009/10 financial year (Wolvaardt 2008).

\section{Tshivenda NLU}

- The NLU published a draft of the first volume of a bilingual Tshivenda/English dictionary during the 2004/2005 financial year, after which copies of the draft were disseminated to stakeholders for comments and suggestions (PanSALB 2004/2005: 38). The project was completed in 2005 (PanSALB 2005/2006: 32) and the bilingual dictionary published in 2006 (Wolvaardt 2008).

- The unit subsequently started work on a monolingual Tshivenda dictionary (PanSALB 2004/2005: 38) that is still in progress (Wolvaardt 2008).

\subsection{NLUs: Management Forums}

After consultations in 1996 with the former editor-in-chief of the Bureau of the WAT, Dr Dirk van Schalkwyk, the author (then of the Department of Arts, Culture, Science and Technology) suggested that a management committee be created to oversee the lexicographical processes. The suggestion - involving the establishment of a co-coordinating lexicography board consisting of the eleven editors-in-chief of the eleven NLUs, with the Director-General of DACST (or his delegate) as chairperson and a member of DACST (i.e. a staff member of the National Terminology Service) as secretary of this board - was presented to the Portfolio Committee (Alberts 1996). This board was, however, not established as the National Lexicography Units Bill was incorporated into the PanSALB Amendment Act of 1999.

There is, however, a need for a coordinating body to encourage coordination and to share problems and solutions. The present incumbents of editors-inchief created such a committee, namely the LexiEditors' Forum, and they all served ex officio in the Forum. The PanSALB Board approved the establishment of the LexiEditors' Forum and encouraged the NLUs to cooperate with each other in matters related to lexicography development (PanSALB 2005/2006: 26). The CEO of PanSALB also attends the meetings of this Forum.

The LexiEditors' Forum is a discussion and consultation group that en- 
ables editors-in-chief to share their experiences and information about lexicography and the operation and progress of their particular NLU, as well as seek solutions to the challenges they all face in their work. The aim of this Forum is therefore to create better working relationships among the NLUs and to discuss issues of mutual interest (PanSALB 2004/2005: 38; 2005/2006: 26).

The NLUs responsible for the four most marginalised languages, namely Tshivenda, Siswati, isiNdebele and Xitsonga also formed a committee in order to collaborate on matters affecting their units and languages (PanSALB 2004/2005: 38).

\subsection{NLUs and Terminology development}

Several factors influence the development of terminology in the (South) African languages. Most of these factors are of a political and sociolinguistic nature. In the past, terminology development in South Africa was hampered by a number of ideological, historical, and educational factors, the most fundamental of which were the language policies adopted in the Republic of South Africa (RSA) (Mtintsilana and Morris 1988: 109). With English and Afrikaans being the official languages in the RSA up to 1994, the State actively supported terminology development in Afrikaans to try to ensure parity with English (Alberts, Botha and Kapp 2010).

Since 1995 structural and policy factors have had an effect on the practice of terminology in South Africa. Some of the language bureaux were either dissolved or reduced to perform a minimum of functions. The State furthermore accepted its responsibility to also develop and promote the African languages (Alberts, Botha and Kapp 2010).

Government policy in language promotion before 1994 stipulated that the promotion of the African languages was the task of the former national states and the Self-Governing Regions, and not that of the South African Government (Alberts, Botha and Kapp 2010).

In 1998, PanSALB's Lexicography, Terminology and Place Names subcommittee and focus area realised the need for coordinating all isolated lexicography and terminology efforts in the country so as to develop a strategy for approaching lexicography and terminology development for all the official languages in the country (PanSALB 1998: 11). PanSALB subsequently consulted various stakeholders involved in these areas.

The purpose of the Lexicography and Terminology Development focus area was inter alia to provide advice on lexicography and terminology development (PanSALB 2000: 26). PanSALB (2001: 24) later decided not to deal with terminology per se under this focus area, since this was the function of the Terminology Section of the National Language Service in DACST (currently known as the Terminology Coordination Section of the National Language Service (NLS), Department of Arts and Culture). 
The terminologist working in a multilingual society such as South Africa thus deals with conflicting situations. The African terminologies should be developed to enhance the multilingual heritage of the country, but there are too many languages to make this practical and economically viable. There are also very few trained terminologists with even less terminology posts available. Various tertiary training institutions offer official courses in terminology and lexicography, and aspects relating to terminology principles are dealt with in courses such as translation or lexicography. The Terminology Coordination Section (TCS) provides in-house training and will have to offer bursaries on terminology training to students interested in this profession if the country's communication problems are to be solved through multilingual terminology in a variety of subjects or domains (Alberts, Botha and Kapp 2010).

These factors stress the importance of the Terminology Coordination Section as an organisation working on a national basis to document, standardise and modernise the various technical vocabularies used in South Africa (i.e. by means of compiling multilingual polythematic technical dictionaries and providing terminology training to collaborators in the field of terminology). The Language Research and Development Centres (LRDCs) assisted for many years with the documenting of terminology but they were closed down. Language units at governmental departments could assist with the documentation of the terminology of the various departments but they will have to work in collaboration with TCS and PanSALB. The translators working at the National Language Service harvest terminology by means of the translation-orientated terminography process where SL and TL documents are aligned and terminology extracted from both documents. The terms harvested in this way go directly to the national term bank (Alberts, Botha and Kapp 2010).

Some of the NLUs assisted with the compilation of terminology lists, e.g. a draft list of bird names in Siswati (PanSALB 2004/2005: 37) and the collaborative project of the IsiXhosa NLU and the Medical Research Council regarding the translation of a set of English medical terms into Xhosa (2005/2006: 28).

In 2004 PanSALB established a new focus area: Standardisation and Terminology Development to advise PanSALB on and implement projects related to the standardisation and terminology development of the official languages, the Khoe and San languages and South African Sign Language. The key strategic objectives of this directorate involved issues relating to primary standardisation processes, primary terminology development processes and secondary standardisation and terminology development processes. This directorate worked in close collaboration with the Terminology Coordination Section of the National Language Service in the Department of Arts and Culture and other organisations involved in terminology projects in order for the National Language Bodies to verify and authenticate terms (PanSALB 2004/2005: 25). This focus area was shut down with the retirement of the Director heading the section in 2010. 


\section{Future}

\subsection{DAC}

The Department of Arts and Culture through the National Language Service is not in a position to accommodate the NLUs. The Department should do language planning and oversee legislative processes (e.g. a national language policy framework; legislation to protect language practitioners and enhance their working conditions), develop policies and matters related thereto. It should furthermore provide facilities and funding for research into language-related matters (i.e. the HLT endeavours) to improve the language situation in South Africa and to ensure that the constitutional demands for multilingualism are met. Practical language-related work such as dictionary compilation (general as well as for special purposes (terminology)) and translation work should not be done at the NLS. DAC should therefore not take care of the NLUs, translation or terminology services.

\subsection{PanSALB}

The 2003/2004 objective of the Lexicography and Terminology Development focus area was "to create conditions conducive to the development of all the official languages in South Africa" (PanSALB 2003/2004: 6). The focus area (consisting of a Deputy Director and an Assistant Director) and its subcommittee focused on the following strategic objectives (PanSALB 2003/2004: 6):

- Ensuring the appointment of Editors-in-Chief for all NLUs

- Capacity building and training of staff at NLUs

- Putting Information Technology (IT) systems in place for the NLUs

- Providing administrative support to NLUs in terms of provisioning systems, human resource management and financial management

- Supporting NLUs in terms of dictionary production processes

- Facilitating cooperation between NLUs and other bodies

It is clear from information supplied in $\S 3$ that various tasks were successfully undertaken regarding the administrative, financial and technical management of the NLUs. It seems, however, that the current focus area manager at PanSALB experienced problems regarding the administrative management of the NLUs, i.e. "owing to staff shortages, both at head office and at the NLU offices, and the inequitable salaries paid to staff members" (PanSALB 2007-2008: 36) - it is not clear whether the salaries mentioned were that of head office staff or NLU staff. The lack of information on the activities of the focus area 
and of the NLUs after 2007 (compared to previous years) was also an indication of troubled waters (PanSALB 2007/2008: 35-36; 2009/2010: 43-44).

According to the annual report of 2007/2008 the strategic goal of the focus area was "to compile comprehensive monolingual and/or bilingual dictionaries" (PanSALB 2007-2008: 35). Surely PanSALB head office staff was NOT appointed to compile dictionaries but rather to provide support services to the NLUs whose main task is dictionary compilation.

The only measurable objectives of the focus area since 2009 have been "to assist in accelerating the production of dictionaries and other products that could generate income for NLUs in the near future. (To) ensure appointment of new Board of Director (BoD) members for all NLUs" (PanSALB 2009/2010: 43).

The only major event mentioned in the 2009-2010 Annual Report of PanSALB involves the actions taken to appoint new members on the Board of Directors. These include the nomination of new members for Board of Directors for all eleven NLUs; the publication of the preliminary name list for public comments; gazetting of the new BOD members, and the inaugural meetings of the new BoD members (PanSALB 2009/2010: 43-46). No mention was made of any other activities or achievements.

It has been difficult to obtain information on the dictionaries compiled by the various NLUs. It therefore seems as if PanSALB is no more in a position to create a working environment conducive to dictionary production.

\subsection{Management forum}

At present the editors-in-chief are ex officio members of the LexiEditors' Forum. It might however be advantageous to create another management structure with an enhanced membership structure, involving the following persons:

- Chairpersons of the Board of Directors

- Editors-in-Chief (as managers of the NLUs)

- Final Editors (as chief lexicographers)

- Directors responsible for Finances on the BoDs

In 1991 the Bureau of the Woordeboek van die Afrikaanse Taal requested a feasibility study to determine the need for an institute for lexicography (see § 3.7; Alberts 1993). At the time it transpired that the respondents did not want another bureaucratic institution. The idea of such a South African Institute for Lexicography (and Terminography) might, however, be justifiable in the current situation, seeing that there is no existing institution that is eager to take responsibility for the NLUs.

A South African Institute for Lexicography (and Terminography) could be a virtual office managing all the NLUs as well as terminology services (see $\S 3.12$; § 4.4). It has been difficult to determine what type of dictionaries were 
published, are ongoing or in a planning phase - a national register on lexicographical and terminographical projects would assist target users.

\subsection{Dictionary services - general and special purposes}

In the past, PanSALB considered lexicography and terminology "to be important building blocks in the development of languages and the promotion of multilingualism" (PanSALB 2000: 26). The Board "established lexicography units as section 21 companies for each official language in South Africa. These units [would] be responsible for the development of dictionaries and terminology for their respective languages" (PanSALB 2000: 26).

There is, however, also a dire need for terminology to be documented in rural, urban and academic fields, where fieldwork is needed to document community-based terminology (indigenous knowledge systems, academic subjects).

Terminologists could be appointed at the NLUs to do fieldwork and to harvest terminology from the speech communities in the rural, urban and academic environment so as to ensure that the existing terminology in these areas is documented and preserved. Each lexicography unit is presently seated at tertiary institutions within the relevant speech community.

Terminologists who are presently working at the Terminology Coordination Section, National Language Service, Department of Arts and Culture (see $\S 4.1)$ could become employees at the NLUs together with the budget allocation from the TCS attached to the specific terminologist to finance the position. These terminologists employed at the NLUs could do fieldwork and harvest terminology in urban, rural and academic areas. Trained terminologists could assist with language-specific terminology development. In cases where terminologists cannot relocate due to logistic problems, they could work online (through the TshwaneTerm/TshwaneLex software) and the envisaged HLT virtual network. The combination of lexicography and terminography work within the same dictionary unit is a model followed by several dictionary offices in Africa (Alberts 2010: 616-617).

\subsection{Department of Higher Education and Training}

According to Bamgbose (1991: 109-111) there is an escalating consciousness in Africa and worldwide of the positive impact of multilingualism, especially in respect of the role of African languages in advancing multilingualism in education. This is reflected in the language policies that acknowledge the need for teaching and acquiring these languages at all levels of education. Terminologists should coin new terms as necessary according to the new function required of the specific language (terms which might not be in existence, especially in technical areas), while lexicographers would be required to write dictionaries. 
In October 2010 the Department of Higher Education and Training held a Roundtable discussion on the position and developmental status of the African languages. According to Language Policy in Higher Education, the use of South African languages in instruction and learning in higher education would require the development of dictionaries and other teaching and learning materials. The meeting acknowledged the existence of various general dictionaries compiled by the NLUs of PanSALB, the various multilingual terminology lists compiled by the terminologists of the TCS of NLS, $\mathrm{DAC}$, and other teaching and learning materials that have since been produced. The question raised by the delegates, however, was whether these dictionaries and materials were enough to meet the requirements of the target group and whether more should be done to meet the requirements of constitutional multilingualism and target users. It was agreed that the State should start with systematic and widespread translation into African languages, supported by lexicography work and terminology development (Alberts, Botha and Kapp 2010; Nosilela 2010).

Delegates also agreed that more funding should be made available to dictionary compilation efforts, albeit general or technical dictionaries. A suggestion was made that the NLUs should be relocated to the Department of Higher Education and Training since PanSALB interpreted its mandate as the monitoring of languages (through the National Language Bodies and Provincial Language Committees) and NOT as the development of languages (Alberts, Botha and Kapp 2010).

\section{Conclusion}

This article started with an overview of the national dictionary offices in South Africa during the bilingual dispensation. It stressed the need for national dictionary offices in all the official languages of the country to adhere to the constitutional multilingual prescripts of post-apartheid South Africa. Next followed a discussion of the drafting of the National Lexicography Units Bill which had led to the establishment of eleven official national lexicography units to document, standardise and preserve the linguistic heritage. These issues were discussed in terms of the past, present and future. Taking into account the value of national dictionary projects, it is obvious that there would be serious implications should these dictionary offices seize to exist.

It is of vital importance that attention should be given to the further training of lexicographers, terminologists and students to enhance knowledge and skills in the principles and practice of general and technical dictionary compilation. Government should give financial assistance for lexicography and terminology awareness campaigns and for the training of practitioners in these fields. Collaboration with national and international experts regarding the standardising of principles and procedures of lexicography, terminography and computational linguistics will enhance the work of practitioners working 
in these fields. Participation in the envisaged Human Language Technology (HLT) virtual network will expedite the HLT endeavours.

By registering various completed, ongoing and planned lexicographical and terminological projects, a clear picture of lexicography and terminology practice will emerge and the duplication of work will be prevented.

Serious consideration should be given to the seats of the NLUs. A logical overseeing institution is the Department of Higher Education and Training since the NLUs are already situated at tertiary institutions. The NLUs need on a continuous basis - proper funding, administrative, technical and IT support and training to ensure excellent lexicography work.

The NLUs need to be given the resources that are necessary to revert to the original idea of producing properly researched, definitive, monolingual dictionaries for each of the official languages instead of compiling all kinds of dictionary products to generate funds (dictionaries that commercial publishers are able to compile much better, and that they are already publishing successfully). The NLUs are essentially the only structures suitable for undertaking major monolingual dictionary products, but they need to be subsidised substantially. The NLUs should be cultural and linguistic databases from which other material for special purposes could be developed. The NLUs should be seen as a cultural investment; a view that is essential if multilingualism is ever going to be feasible.

Consideration should also be given to moving all lexicographical and terminographical activities - even translation activities - to the NLUs in order to provide a proper language service to the citizens of South Africa.

There might at this stage be room for an independent (virtual) South African Institute for Lexicography and Terminography to manage the decentralised NLUs situated in their respective geolinguistic areas at tertiary institutions. It is also the author's view that the time is ripe for the establishment of such an institute, as this might promote citizen awareness of the value of lexicography and terminology for communication.

\section{References}

Alberts, M. 1993. Feasibility Study: Institute for Southern African Lexicography. Stellenbosch: Bureau of the WAT.

Alberts, M. 1996. Background Information on the Drafting of the National Lexicography Units Bill. Unpublished document. Pretoria: DACST.

Alberts, M. 1997. Reallocation of Funds to be used for Lexicography Training and Lexicography Awareness Campaign. Pretoria: DACST.

Alberts, M. and M. Jooste. 1998. Lexicography, Terminography and Copyright. Lexikos 8: 122-139.

Alberts, M. 2003. Appointment of Editors-in-Chief. Unpublished paper read at the PanSALB workshop held at the Sinodale Building, Visagie Street on 3 March 2003 in Pretoria.

Alberts, M., W.F. Botha and P.H. Kapp. 2010. Historical Experiences in Developing Afrikaans as a Language. Paper presented at the Roundtable on African Languages, organised by the Depart- 
ment of Higher Education and Training and held at Unisa, Sunnyside Campus, Pretoria on 22 October 2010.

Bamgbose, A. 1991. Language and the Nation: The Language Question in Sub-Saharan Africa. Edinburgh: Edinburgh University Press.

DAC. 2002. National Language Policy Framework, Final Draft. Pretoria: Department of Arts and Culture (DAC)

DACST. 1996. National Lexicography Units Bill. (As introduced) [B 103-96]. Wetsontwerp op Nasionale Leksikografie-eenhede. (Soos ingedien) [W 103-96]. Pretoria: Minister of Arts, Culture, Science and Technology, Department of Arts, Culture, Science and Technology (DACST).

DACST. 1997. PanSALB and the Tabling of the National Lexicography Units Bill. Unpublished document (5/3/2/7/2/3). Pretoria: Department of Arts, Culture, Science and Technology (DACST).

Mtintsilana, P.N. and R. Morris. 1988. Terminography in African languages in South Africa. South African Journal of African Languages 8(4): 109-113.

Nosilela, B. 2010. Current State of African Languages in Institutions of Higher Learning. Paper presented at the Roundtable on African Languages, organised by the Department of Higher Education and Training and held at Unisa, Sunnyside Campus, Pretoria on 22 October 2010.

PanSALB. 1998. Annual Report.

PanSALB. 1999. Annual Report. Pretoria: Pan South African Language Board (PanSALB).

PanSALB. 2000. Annual Report. Pretoria: Pan South African Language Board (PanSALB).

PanSALB. 2001. Annual Report. Pretoria: Pan South African Language Board (PanSALB).

PanSALB. 2002. Annual Report 2001/2002. Pretoria: Pan South African Language Board (PanSALB).

PanSALB. 2004. Annual Report 2003/2004. Pretoria: Pan South African Language Board (PanSALB).

PanSALB. 2005. Annual Report 2004/2005. Pretoria: Pan South African Language Board (PanSALB).

PanSALB. 2006. Annual Report 2005/2006. Pretoria: Pan South African Language Board (PanSALB).

PanSALB. 2008. Annual Report 2007/2008. Pretoria: Pan South African Language Board (PanSALB).

PanSALB. 2010. Annual Report 2009/2010. Pretoria: Pan South African Language Board (PanSALB).

Wolvaardt, J. 2008. Summary of NLU Products and Ongoing Projects (Updated July 2008). Unpublished document. LexiEditors' Forum. 